\title{
Problems and Solutions in Dual Educational Transformations in Contemporary China
}

\author{
Chen Kaiju ${ }^{1, *}$, Ru Ying ${ }^{2}$ \\ ${ }^{1}$ Center of Business Culture and Philosophy of Culture, Institute of Hermeneutics, Guangdong University of Foreign Studies Institute of \\ Advanced Studies, University of Chinese Academy of Social Sciences, Guangzhou, China (PRC) \\ ${ }^{2}$ School of English for International Business, Guangdong University of Foreign Studies, Guangzhou, China (PRC)
}

Email address:

200010931@oamail.gdufs.edu.cn (Chen Kaiju),ruying0509@gmail.com (Ru Ying)

*Corresponding author

\section{To cite this article:}

Chen Kaiju, Ru Ying. Problems and Solutions in Dual Educational Transformations in Contemporary China. International Journal of Literature and Arts. Special Issue: Humanity and Science: China's Intercultural Communication with the Outside World in the New Era. Vol. 8, No. 2, 2020, pp. 62-69. doi: 10.11648/j.ijla.20200802.15

Received: February 27, 2020; Accepted: March 11, 2020; Published: March 31, 2020

\begin{abstract}
The transformation of social civilization requires corresponding transformation of education. Contemporary China is undergoing a dual transformation of modernization and post modernization of educational models, each of which involves educational concepts, educational goals, disciplines and settings and a series of other factors, such as teaching methods, the relationship between teaching and learning, and the evaluation of teaching effectiveness, all of which constitute a systematic project. The modernization of education in China can be achieved by learning from the modernized educational models in developed Western countries and regions and by promoting international cooperation in education. As there is no established model for postmodern educational transformation to learn from, we need to take the initiative to face the problems emerging in the transformation and explore them actively in order to find solutions in the context of international cooperation. The modernization of education requires us to shift from the traditional focus on knowledge to the equal emphasis on knowledge and skills together, and to cultivate students' self-directed learning ability. Postmodern educational models are on the way to form up. However, if we make full use of new media and information technology to cultivate students' aesthetic consciousness and ability

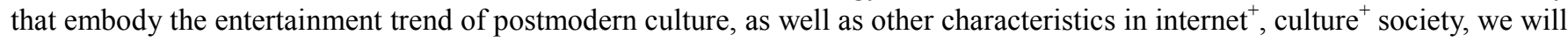
probably achieve a great progress in the transformation.
\end{abstract}

Keywords: Educational Transformation, Dual Transformations, International Collaboration, Self-directed Learning, Aesthetics

\section{Preamble}

Education enables humans to acquire knowledge, open up their minds, improve their cognitive abilities and practices, and exercise the development of human intellectual potential in the course of human life, aging, illness, and death, so as to help humans to achieve self-realization; the effectiveness of education directly affects the development of material and spiritual civilization in society. Education is related to the growth and self-realization of each member of the society. Therefore, Education as a public issue is of crucial importance in human society, and any significant change in education has become an increasingly important event in social public utilities since it will eventually bring changes to the development of social productivity.

Under the grand social security system of taking care of social members' birth and death, growth and aging, health and entertainment, education, in particular, sees to the development and fulfillment of life, which, in turn, forms and generates the totality of social capacity of production and innovation that sustain and push forward the course of development in any given society. With the evolution of the society, changes must be made accordingly in education to cope with, enhance and lead social practices, which are manifested especially at the transition of civilization, and the transformation of social form and cultural pattern.

The development of social civilization and the 
improvement of human production and living standards will inevitably lead to corresponding new requirements on education. With the evolution of education and changes in cultural patterns, education also needs to make timely and appropriate transformations to meet the needs of social reality. From the perspective of education in a strict sense of scale, human society has undergone a transformation from an educational model adapted to empirical cultural pattern in an agricultural civilization to a model adapted to a rationalist cultural pattern in an industrialized civilization. Although this transformation has not been completed on a global scale - the industrialization transformation in the majority of the third world countries and regions is still in progress-at the same time, since the middle and later periods of last century, in countries and regions in the developed world as well as some fast developing areas, industrial civilization has been transiting to information technology oriented post-industrial era, and correspondingly, new requirements have been put forward for the transformation of educational models.

After decades of continuous development since the end of 1970s, China is currently in a state of coexistence of two types of civilization transformation. On one hand, China's modernization and industrialization are progressing rapidly, but due to the profound and long tradition of agricultural civilization with geographical and demographic diversities, the transformation of social industrialization in mid and west China is far from complete; on the other hand, since the end of last century, early opening-up regions in the coastal and eastern areas have already entered the post-industrial stage. This leads China's education to a double transformation: from traditional education to modern education, and further to the education model corresponding to the information civilization age.

Over the past decade or so, with its opening up reform and policy, China has carried out extensive and intensive international cooperation in many fields, education included. It is against this background-the dual transformations of civilization and the deepening of international cooperationthat the paper discusses the tasks, problems, and countermeasures emerging during the process of the dual transformations of educational model.

\section{The Dual Transformations of China's Education}

Since human beings formed societies, they have relied on the power of various social groups to create glorious civilizations. The strong collective power of societies has enabled humans to conquer and tame physically incomparable animals (such as wolves, tigers, leopards, etc.), insurmountable mountains and rivers, and other natural phenomena to such a degree that contemporary ecocriticism scholars urged the need for ecological protection of nature including the above-mentioned aspects [1]. Throughout the life cycle of human life, aging, illness and death, education and other industries in production labor have been taking main-staying effect in human social life. The more the society progresses, the more advanced the production is; the more complex the organization is, the richer the culture will be, and the more diverse and high-quality education is needed to support all aspects of production and life.

Affected by the decisive influence of the transformation of the mode of civilization and the replacement of corresponding cultural pattern, education has been undergoing drastic changes and even apparent transformations. Human civilization has gone through stages of primitive civilization, agricultural civilization and capitalist civilization, which respectively correspond to the cultural patterns of naturalist religious worship, empiricism, rationalism, innovation and pan-amusement. The educational model corresponding to each civilization mode can be referred to as textbook-oriented, teacher-centered and student-centered respectively [2].

However, this division is by no means absolute, because cultural pattern, which refers to "the relative stable ways conventionalized by a particular people in a particular period of time, including the spirit of the time, shared values, customs and habits, ethnic norms, and so on. In short, it is the way of their existence and/or living", [3] is always based on the synthesis of the former." is always based on the synthesis of the former. Rather than completely abandoning various factors of the former, the latter is a sublation, adding new content suitable for social civilization and cultural pattern, which reflects the requirements of times. "Educational transformation is a holistic change in education, which refers to the qualitative change between different educational forms or a partial qualitative or quantitative change that occurs within the same educational form. For instance, in the historical evolution of human education, the transition from traditional education to modern education, from agricultural social education to industrial social education and post-industrial social education, from traditional education to modernized education, etc., are all qualitative changes between educational forms. The two types of education before and after are different forms with significant differences." [4]

The first stage is the textbook-oriented model. Typical examples are witchcraft under primitive civilization, education under religious worship, and moral inheritance education under farming civilization. It is manifested in the education process around classics or teaching materials and preaching to students. Teachers read and recited the classics and instilled them into students as knowledge, and students just lapped up information without digesting it. As for how much students could understand, how it was obtained or how to make use of it, it primarily depended on the students' capabilities. This teaching model is irresponsible for its effects. The second stage, teacher-centered stage, began under the agricultural civilization, developed and matured in the period of industrial civilization. Because of the differentiation of the social division of labor and the urgent need for practical need-oriented knowledge and skills, new requirements arose for educational content. Education must serve social practice, and it is reflected in the link between teaching and learning. Within them, the internship, which tests the effectiveness of 
teaching and learning, is the most convincing part. With the accumulation of knowledge and development of technology and the further division of disciplines, the third stage, student-centered model, emerged in time. It posed new and higher requirements for education: to cultivate students' learning and ability to process materials and acquire knowledge, to help students maintain the awareness of not being overwhelmed by diversified materials and knowledge, thereby helping them to achieve sustainable development of learning. The transition from traditional "textbook-oriented" educational model to "teacher-centered" and "student-centered" models signifies the transition from the traditional agricultural educational model to a modern educational model that is compatible with industrial civilization. This transformation has been completed in major developed Western countries and regions. Teaching strategies, such as "student-centered teaching", "task-based teaching", "self-directed teaching" and "process evaluation" are examples of specific practices under the transformed educational model. Drawn on from the large number of researches on teaching and learning, we can conclude that contemporary Chinese scholars have generally recognized this transformation and gradually implemented "teacher-centered" and "student-centered" teaching in practice.

At the same time, due to the sustained and rapid development of China's economy and society, the eastern and coastal regions, as the first areas carrying out opening-up reforms, have gradually entered the post-industrial or information society since the new millennium. Confronted with the new situation with distinctive "internet+" and "culture+" features, the cultural pattern and educational model must also experience inevitable transformations accordingly. Such transformations, even in developed countries and regions, are a relatively recent phenomenon in terms of civilization mode, cultural pattern and educational model. Thus, there is no established model for us to learn from. However, due to the unfinished nature of China's industrial civilization, there are also fewer rules and regulations on the transformation process. That is to say, in the face of new transformation, China has the "late-comer" advantage. By making full use of the opportunity of the new transformation, we can avoid some of the shortcomings existing in the modernization process and attain "late-comer" privilege.

In fact, the practice of real social development is exactly this way: make full use of new media and new technologies to adapt to the transformation of creative industries and form new competitive industries, where we have partially achieved the success. For example, in terms of new information and creative industries, the U.S. and China have made great achievements and are taking the lead throughout the world. Taking the corporate sector as an example, the United States has new industrial giants such as Facebook, Google, Microsoft, IBM, and Apple, while China has its representatives such as Tencent, Alibaba, Jingdong, Lenovo, Huawei, etc., but so far there are few rivals in other countries for the time being. Accordingly, the new education transformation should be guided by emerging and future industries and take the initiative to change. However, it's difficult to implement the transformation through learning from international partners. Instead, we need to actively explore and experiment with new developments and new needs to find feasible ways. This is the fourth state of education: "Teaching students to learn and innovate". That is, to meet the requirements of education in the knowledge-information age, in addition to cultivating students' ability to learn, judge, and integrate knowledge, educators must also cultivate their ability to think and develop ideas.

The duality of educational transformation in contemporary China refers to the dual transformations of education that is compatible with the dual transformations of our society: the traditional agricultural civilization is transiting to modern industrial civilization; and the coastal and first-mover regions are transforming from modern industrial society to knowledge-information postmodern society simultaneously. Education, at the same time, is also experiencing a change from "teacher-centered" model compatible with agricultural civilization to "student-centered" model adapted to industrial civilization: highly professional and specialized social labor division requires education to develop students' learning ability, and pushes forward "students' innovation-oriented" education to be adapted to postmodern society. This is especially true of Western education that advocates learning ability and the awareness of not being overwhelmed by rich materials and knowledge. The knowledge-information era requires education to promote students to innovate in addition to acquiring knowledge and thinking critically. "China's educational transformation has the connotation of dual transformation in time and space. It must not only accomplish the task of transforming the educational model compatible with agricultural society to one that is compatible with industrial society, but also meet the challenges of informatization, eliminate the negative factors of education in industrial society, and integrate education in information age into education reform, thereby achieving dual transformation... We need to transform from self-dependent education to self-directed education in order to enlighten individuals and cultivate rational subjective consciousness. We also need to avoid the over-development of individual subjectivity and use intersubjectivity to guide a healthy development of individuals. Therefore, we should transit from individualized subject education to classified education" [5].

Specifically, this dual transformation can be subcategorized into four areas:

A. The shift from "knowledge-centered" model to "ability-centered" model (to solve practical problems);

B. The shift from "teachers teaching students" model to "teachers-guiding-students-to-learn" model;

C. The shift to the cultivation of the students' ability to search, select, acquire and integrate knowledge;

D. The shift from "students' correct analysis and problem-solving" model to "individualized and innovative problem-solving" model.

These macro-level educational transformations in practice are to solve the practical problems often encountered in the 
teaching process: such as teachers' scholasticism and students' weariness due to unclear teaching goals or objectives; improper teaching and inefficient learning due to improper methods; "high scores with low abilities" due to poor evaluation methods; and unsatisfactory teaching effects, etc., which eventually lead to poor education results: On the one hand, students cannot meet social needs, resulting in employment difficulties; while on the other hand, education fails to provide socially needed talents. The postmodern cultural pattern exposed another perplexing problem, i.e. the educational model which drilled knowledge into students' brain adds up to their boredom. Regarding the problems in these two transformations, the specific issues and ways of implementation are discussed below.

\section{Transformation of China's Education Under the Perspective of International Cooperation}

The smooth progress of the transformation of industrial civilization in China's economic and social development over the past decades has implemented the primary education transformation, that is, the modern transformation of education, to a considerable extent. It refers to the transformation from moral education based on the empirical cultural pattern compatible to agricultural civilization to knowledge-skills based education on rationalist cultural pattern compatible with industrial civilization. "The core of the purpose of education is the question of what kind of people should education cultivate and breed. The transformation of educational purpose means the transformation of people. Therefore, the transformation of education should be centered on the transformation of people" [4]. This directive factor of the modern transformation of education is determined by the transformation of social civilization. Particularly in higher education, employment has put forward corresponding transformation requirements on higher education: designs of disciplines and knowledge-skill requirements should meet the social industry's demands for talents.

Developed countries and regions in the West were the first areas that carried out industrial civilization. The industrial division is meticulous, and the corresponding modern educational model is also complete, offering a mature model for us to learn from. Through learning and cooperation, we can better achieve the transformation of modern education. The transformation of education in a transition from the agricultural civilization to the industrial civilization needs to solve a series of problems in traditional education, specifically, the first three types of problems listed in the previous section:

A. The shift from "knowledge-oriented" model to "ability-oriented" model (the ability to solve practical problems);

B. The shift from "teacher-centered education" to "student-centered education";

C. The shift to the cultivation of students' ability to search, select, acquire and integrate knowledge.
In terms of educational and teaching practice, it is necessary to carry out a comprehensive change, ranging from disciplines, majors, courses, teaching materials, teaching methods to evaluation systems, practical ability, self-directed study and research-based study, etc., to eliminate the age-old problem. Educators should define the cultivating goals as employment-oriented in modern industrial society, grasp the basic content or judgment indicators of educational transformation from a macro perspective. It covers changes in core concepts, training methods, evaluation methods, including the integrity of internal change in institutional mechanisms [6]. The core content of education has been transformed from knowledge-transferring to knowledge-skill combined, that is, the problem-solving skill and know-how are added to the traditional emphasis on know-what. Therefore, teachers and educators must "change from knowledge givers to skill trainers; from directors to facilitators, from practitioners to researchers, from teachers of classics to teachers of man" [7]. The major place of teaching has also shifted from the traditional one-way knowledge transfer of students listening and taking notes to the emphasis on both knowledge and skills. "A major sign of the transformation of classroom teaching is to move from 'lecturing-directed type' to a 'learning-directed type' classroom. To achieve this goal, three major transformations must be implemented: from the "discipline-orientated" type to the "learning-oriented" type in curriculum design, from the "teacher-lecturing-student-oriented" to "student-learning -and-teacher-guiding" in teaching relations; from "stuff exercise type" to "ecological development type" [8]; the evaluation system for teaching effects must also be transformed, and "multi-dimensional evaluation is needed to forge students' innovative personality" [9]. "Multi-dimensional" here refers to students' ability to analyze and solve problems on the basis of traditional focus on knowledge assessment. It also includes the ability to search information, identify useful knowledge, and integrate what has been identified useful for them.

Although we have basically reached consensus on the theoretical perspective of the above-mentioned specific aspects in education and teaching, the actual implementation of the transformation is far from easy. Concerning China's educational practice, various problems, especially the large-scale classrooms, indoctrination, and knowledge-oriented evaluation system resulting in mechanical teaching model, are not fundamentally different from the traditional teaching.

The existing model, which has long been accustomed to traditional teaching, has a systemic feature, which means the radical change of it involves all aspects of education and teaching. As a systemic project, it will inevitably make people confused and disoriented. In fact, in view of this, we can achieve transformation through international cooperation, especially cooperation with universities in developed European countries and the United States. The realistic basis of the cooperation is China's ever-opening national policies; especially since China's accession to the WTO, extensive and 
intensive international cooperation has been launched in many areas of our society, and education is no exception. Nowadays, almost all colleges and universities have launched diversified forms of educational cooperation with foreign countries, in particular with those in developed Western areas. Western educational concepts, discipline construction and settings, teaching materials and teaching methods, evaluation systems, continuing education and employment, have been well-known in China's education field today, especially in colleges and universities. In many aspects, there has been sufficient exchange of experience and learning that have been applied into educational practice. Broadly speaking, it is to realize the modern transformation of education in China by adopting the strategy of educational internationalization. Through in-depth international cooperation in education, we will establish an educational talent system, increase the international competitiveness of our education, promote a change in teaching concepts, and improve and enrich education in China. In fact, many colleges and universities in China have begun to attach importance to the teaching process (such as increasing the proportion of daily performance scores in course grades), to task/practice-based assignments (as part of daily performance scores included in final course scores), and to reducing the proportion of memory-based requirements and final exams. These specific measures are some of the transformational practices of education through learning from foreign teaching experiences.

In short, the transformation of modern education in China can be rapidly advanced on the basis of fully learning from and drawing on the mature experience of modern education in the West in order to achieve the transformation in the above-mentioned aspects. With closer and deeper cooperation between Chinese and foreign education and teaching, (such as the establishment of parallel courses, and even Chinese and foreign teachers jointly teaching the same course), all aspects of teaching, including teaching materials, teaching methods and evaluation, will be combined together to promote new educational model in China. China will directly learn from them and reform the original education and teaching modejust in the way how China has developed its economic and social mode-and certainly will complete the transformation quickly to be in line with international standards.

This transformation, without doubt, has a long way to go, especially when it is far from implementing a corresponding change in elementary education. Therefore, on the one hand, we should vigorously promote a more comprehensive transformation of higher education in order to promote the transformation of the entire education field; on the other hand, research on modern transformation of China's educational theory and practice should be extended to the entire education sector so that the overall transformation of education will be accelerated. At the same time, small-sized class and personalized education in Western education system means much higher investment than now in China. It requires more comprehensive investment from the society, which will certainly require a much larger allocation of educational resources than now. Similarly, the universal credit system in higher education means providing students with a wide variety of choices. This alone will inevitably lead to fierce competition for resources with other sectors, the public service industry included. In the short term, it may be difficult to achieve social consensus and provide sufficient investment for education.

\section{Major Problems and Measures in Postmodern Transformation}

As mentioned above, in a series of divisions of educational models and the transition of various models, no absolute clear line exists between two adjacent models. Furthermore, the latter is a sublation of the former model, substituting and removing the obsolete and unreasonable parts with new contents that suit the need of social civilization. That is, the latter model is based on the previous one, not an absolute abandonment.

addition to the modern transformation, the arrival of postmodern society has brought us the second transformation of education, i.e., the transformation to the postmodern educational model, which is the fourth item (subcategory D in part 1) mentioned earlier in this paper: the shift from "correct analysis and problem-solving" to "individualized and innovative problem-solving".

The characteristics of education transformation in a postmodern society are determined by the characteristics of the civilization in the information society: in a highly convenient consumer society with highly developed material production and diversified service channels, especially in the "internet+" and "culture+" era, familiar to people in recent years, new features and aesthetic orientations have become people's new needs. Only the innovation and aesthetic abilitythe requirements of postmodern entertaining trends of culture for labor and products-can endow products and services with a unique taste and aesthetic meanings, such as taste, style, thereby attracting consumers' attention and realizing the symbolic and cultural value of products and services. This transformation mainly centers on two aspects: the cultivation of students' innovation and aesthetic ability, which is the fourth stage, "guiding students to learn and innovate", as mentioned earlier in this paper.

Like postmodern civilization, the transformation of postmodern education model is a new issue for the whole world, and people need to move forward in exploration. In the transformation or modernized education, we can learn from the successful experiences of first movers in developed Western countries; however, the characteristics of the postmodern society have not been fully matured, because the postmodern society is still in the formative stage. On the one hand, there is no ready-made postmodern educational model to learn from, so, we need to explore with the Western developed countries and regions in the postmodern social transition; but on the other hand, it proves that we have equal opportunities for the reason that we have not completed the transformation of the modernized education and consequently 
have fewer constraints than those with established models. Therefore, we have the late-comer advantage. As long as we seize the opportunity, we will likely avoid the shortcomings existing in the modern educational model and even surpass other countries.

How to achieve the postmodern transformation of education? In the face of this brand-new project, we cannot yet give a positive answer. This issue can only be treated from a historical, realistic, and future-oriented perspective, in order to find a solution to it. The so-called "historical" perspective refers to examining the educational transformation that has taken place in human society in order to predict the scope, content and steps of postmodern educational transformation. Meanwhile, traditional knowledge and culture is an important content of education heritage. The "realistic" perspective refers to real practices that are rooted in continuous development in real life, especially in the healthy, sustainable development in various aspects of an economic society in China. The newly emerged things (in the spheres of industry, technology, needs, etc.) are maintaining an interactive relationship between education and social reality. The "future-oriented" perspective means that education should be oriented towards emerging and future industries, and actively make adaptations to realize the transformation of education from serving the society to leading the society. In particular, it's necessary to pay close attention to new media and new technologies, which are in line with the transformation of innovative industries; and to stick to the new characteristics of the era, such as "internet+", "culture+", aesthetic and entertaining characteristics, and so on. Specifically, the main aspects are tentatively proposed as follows,

1) On the basis of the transformation of modern educational and teaching models, we will promote the transformation of postmodern models. In particular, we should borrow and learn from the task-based teaching methods and the cultivation of students' self-directed leaning ability to complete the leaning of basic knowledge and the fostering of basic skills. This is the starting point of the transformation of postmodern education and teaching. Without this foundation, innovation is impossible; instead, a worsening phenomenon will occur of a new generation without mastering basic knowledge or skills. This is also what is repeatedly emphasized in previous section: the transformation is a sublation, not absolute abandonment.

2) Second, special attention should be given to making full use of new technologies to enable students to acquire knowledge. At the same time, teachers and schools should keep pace with the times, renovate education and teaching methods, improve proficiency and achieve common progress. This attitude is a necessary prerequisite for the entire educational transformation. In fact, the informatization of education management (paperless office), multimedia teaching methods (PowerPoint, MOOC, electronic courseware), hypertext (multi-text of teaching content, hypertext links), and intelligentization of students' learning tools (from
E-dictionaries to E-bibliographies, micro-media learning platforms, etc.) have been used partially in education, teaching and learning. It is foreseeable that this type of intelligent teaching platform will be more abundant, complex and convenient. We should make full use of micro-media, direct students' enthusiasm on micro-media to teaching practices and then achieve good teaching results [10].

3) We need to keep in mind that innovation and originality should be cultivated gradually and cumulatively. We cannot expect to achieve a renewed effect in the short time. The overnight transformation of "Great Leap Forward" type is neither possible nor necessary, and in fact, is often harmful. It is necessary to establish corresponding fault-tolerant and trial-and-error mechanisms in the innovation process. Otherwise, it will be difficult to cultivate students' innovation and originality by simply sticking to the traditional method of focusing on knowledge-memorization and standard-answers evaluation.

4) The new educational models should encourage cultivation of the students' innovation and originality. We need to attach importance to the study of real social life, excellent traditional culture, and art during the educational process because they are the sources of meanings. As for the importance of art, scholars have pointed out, "Art takes a particularly important position in the spiritual life of the ancient Chinese. The ancient Chinese regarded art as an important way for people to pursue an artistic life, and even considered the art as the highest forms of an ideal life" [11]. In the process of education and teaching, attaching importance to the above aspects is conducive to creating an innovative culture-- "one of the tasks of educational innovation is to build a strong innovative culture." [12]

5) Due emphasis should be given to the cultivation of students' autonomy in the process of learning and innovation and change the traditional "knowledge giving" type to "teacher-guiding-students" type. Teachers and students are required to closely focus on the central task of teaching and learning, and to add the cultivation of innovation and originality to the traditional process of acquiring knowledge and fostering skills. Therefore, the task of teaching and learning is increased, not reduced, in a postmodern educational model.

6) Post-modern education must be based on the students' happy learning, the highest and most difficult state in teaching and learning. Traditional indoctrination has a great repressive nature on people's pursuit of happiness, which is the root cause of students' tiredness of study. In postmodern society, the living pace is faster, and the competition for study and labor production are more intense. Only happiness can offset the pressures caused by such fast-paced, and high-intensity work and life. "The post-modern society presents significant features of production culture, symbolization of consumption, and cultural entertainment. Although there are sharp 
criticisms from scholars such as Postman, the entertaining trend of postmodern culture and even the trend of pan-amusement have not slowed down. Instead, it becomes more and more distinct. People are much freer to enjoy the entertainment of culture at anytime and anywhere. The full publicity of human nature in postmodern culture renders 'I am free, and I am happy' as the main theme of social and cultural life". "...with the arrival of information era, post-modern social culture has undergone tremendous changes: exquisite and classic traditional culture has gradually replaced by the pattern of popular culture. The consumer society shifts from excessive commodities to excessive information, which yearns for public attention, resulting in the entertainment of popular culture." [13] The transformation of postmodern educational model must also conform to the characteristics of entertainment in post-modern society and culture. “... (Schools and teachers) should cultivate students' personality from a young age, cultivate student's creative thinking, and propose different goals for each student, so that students can achieve "happy learning"' [14]. On the basis of creative and autonomous learning, students can gain satisfactory results, get delights in learning and then sustain high-intensity learning.

In addition, as globalization continues to evolve and the status of our country in the international community improves, we must continue to strengthen international cooperation, face the future together with countries and regions encountered with postmodern transformation of education, and explore and promote the transformation---in fact, good results have been achieved in this regard. The Bask Program is a typical example of successful international cooperation. In this program a new way of research (cross-country, cross region, cross-culture and cross-subject) is adopted to study the environment, ecology, and human environment of Yunnan Province, and it has obtained great achievements. Both teachers and students from China and United States have benefited from this program [15].

\section{Concluding Remarks}

Under the macro background of economic and social modernization and postmodern transformation, contemporary China is undergoing a dual transformation of the modernization and post modernization of educational models, each of which involves educational concepts, educational goals, disciplines and settings, teaching materials and a series of other factors, such as teaching methods, the relationship between teaching and learning, and the evaluation of effectiveness of education and teaching. It is a systemic project. The modernization of education in China is rapidly evolving. Many of the problems emerging during the process of transformation can be solved by learning from the modern educational model of Western developed countries and regions in the course of deepening international cooperation in education. At the same time, together with Western developed countries and regions, the east-south coastal developed areas in China are facing the postmodern transformation, which in turn, will pose requirements to the transformation of education. However, in this respect there is no established model for us to learn from, thus we need to take the initiative to face the problems and actively explore them, and then find solutions to them under the context of international cooperation.

The modernization of education pushes forward a shift from the traditional focus on knowledge only to the equal emphasis on knowledge and skills together to cultivate students' self-directed learning. Postmodern education transformation does not yet have a mature model, but it can be certain that if we make full use of new media and information technology, as well as features of internet + and culture + society, and lay emphasis on the cultivation of the students' aesthetic consciousness and ability, we will make steady progress in the transformation.

\section{References}

[1] Chen Kaiju; Chen Weiqiu. (2015). A Cultural Critique on Eco-criticism. Philosophical Studies, V5 pp 122-126.

[2] Shen Zhangming \& Duan Guanzhou. (2016). "Role Crisis and the Transformation of Modern Education". Journal of Liaocheng University (Social Science Edition), 01: 122-128.

[3] Yi Junqin. 2001. Cultural Patterns: A philosophical Perspective. The Northern Forum, 01: 4-10.

[4] Feng Jianjun. (2012) "Education Transformation, Human Transformation and Civic Education". Journal of Higher Education, 33 (04): 9-15.

[5] Feng Jianjun. (2011). "The Duality of Education Transformation in Contemporary China". Journal of Nanjing Normal University (Social Science Edition), 03: 104-109.

[6] Sun Qihua. (2011) Reflection on Education Conversion. Jiangsu Education Research. 34: 3-6.

[7] Zheng Shuhong. (2004). On the Renewal of College Teachers' Roles Based on the Education Transformation. Journal of Putian University. 01: 29-31.

[8] Lin Huisheng. (2013). "On the Three Transformations of 'Learning-Oriented' Class". Journal of Curriculum and Instruction. 10: 11-14.

[9] Chen Wenyuan. (2012). "On University Student Evaluation in the Perspective of Education Transformation". Research in Educational Development. 32 (09): 76-80.

[10] Chen Zhenghui. (2014). "Study of the Innovation of Education in the "Microblog Era". Jiangsu Higher Education. 04: 95-96.

[11] Zhu Zhirong. (2012). Philosophy of Chinese Art, Shanghai: East China Normal University Press.

[12] Zhou Zuoyu. (2012). "Educational innovation of Nobel Laureates", Journal of National Academy of Education Administration, 05: 3-11.

[13] Chen Kaiju, Zhang Jin. (2016). "A Critique on Post-Modern Cultural Pan-Amusement", in Philosophical Studies. V7 pp 120-126. 
[14] Cheng Huandi. (2015) "Inspiration of Naisbitt's Educational Theory for Chinese Education Development". Journal of Langfang Normal University (Social Sciences Edition, 31 (03): 126-128.
[15] Roland, Eric; Merrill, Peter. (2015). Development and Achievement of Innovation Program Supported by Four Schools from China and United States--An Analysis of BASK Program. Education of Innovative Talents, 02: 92-95. 